\title{
Relationship between predicted oxygen uptake and cigarette smoking in Japanese men
}

\author{
Nobuyuki Miyatake $^{1^{*}}$, Takeyuki Numata ${ }^{2}$, Zhen-Bo Cao ${ }^{3}$, Motohiko Miyachi $^{4}$, Izumi Tabata $^{5}$ \\ ${ }^{1}$ Department of Hygiene, Faculty of Medicine, Kagawa University, Kagawa, Japan; \\ *Corresponding Author: miyarin@med.kagawa-u.ac.jp \\ ${ }^{2}$ Okayama Southern Institute of Health, Okayama Health Foundation, Okayama, Japan \\ ${ }^{3}$ Faculty of Sport Sciences, Waseda University, Saitama, Japan \\ ${ }^{4}$ National Institute of Health and Nutrition, Tokyo, Japan \\ ${ }^{5}$ Ritsumeikan University, Shiga, Japan
}

Received 12 April 2012; revised 3 May 2012; accepted 23 May 2012

\begin{abstract}
The link between cigarette smoking and predicted oxygen uptake was investigated using data for 149 Japanese men not taking medication. Cigarette smoking habits were obtained through interviews by well-trained staff. The influence of cigarette smoking on predicted oxygen uptake, predicted work rate and predicted heart rate were evaluated. Predicted oxygen uptake decreased with age. Predicted oxygen uptake and predicted work rate in men who smoked cigarettes was significantly lower than in subjects who did not, after adjusting for age. The differences in parameters did not reach significant levels after adjusting for age and physical activity evaluated by $\Sigma$ [metabolic equivalents $\times h$ per week (METs'h/w)] (predicted oxygen uptake: $p=0.0632$, predicted work rate: $p=0.0873$ ). Cigarette smoking might be a modifiable factor for improving the aerobic exercise level in Japanese men.
\end{abstract}

Keywords: Cigarette Smoking; Predicted Oxygen Uptake; Metabolic Equivalents

\section{INTRODUCTION}

Regular physical activity has been shown to increase high density lipoprotein (HDL) cholesterol and reduce resting blood pressure, triglycerides, abdominal fat, fasting blood sugar, and insulin responses to the oral glucose challenge test [1-5]. In addition, Sandvik L. et al. reported that physical fitness was a graded, independent, long-term predictor of mortality from cardiovascular causes in healthy, middle-aged men [6]. Maximal oxygen uptake is generally considered an accurate and reliable parameter. In the Exercise and Physical Activity Refer- ence for Health Promotion 2006, established by the Ministry of Health Labour and Welfare Japan in 2006, maximal oxygen uptake was considered to be the most significant element of physical fitness related to health promotion and the recommended reference value for maximal oxygen uptake to prevent lifestyle-related disease was reported [7].

Cigarette smoking has become an important public health challenge, and it has been reported that $39.4 \%$ of men and $11.0 \%$ of women are current smokers in Japan [8]. Cigarette smoking is also a strong risk factor for atherosclerosis and cardiovascular disease in a dose dependent manner [9]; however, the relationship between cigarette smoking and aerobic exercise level defined by maximal oxygen uptake has not been fully discussed.

The aim of this study was to explore the link between cigarette smoking and predicted oxygen uptake in Japanese men.

\section{SUBJECTS AND METHODS}

\subsection{Subjects}

We used data for 149 Japanese men $(44.1 \pm 14.1$ years $)$ who met the following criteria from April 2007 to March 2010 at Okayama Southern Institute of Health, Okayama, Japan: 1) underwent anthropometric and predicted oxygen uptake measurements and evaluation of cigarette smoking voluntarily; 2) receiving no medications for diabetes, hypertension and/or dyslipidemia; and 3) provided written informed consent (Table 1).

Ethics approval for the study was obtained from the Ethics Committee of Okayama Health Foundation.

\subsection{Anthropometric and Body Composition Measurements}

Anthropometric and body compositions were evaluated based on the following parameters: height, body 
Table 1. Clinical profiles of enrolled men.

\begin{tabular}{|c|c|c|c|}
\hline & Mean \pm SD & Minimum & Maximum \\
\hline Number of subjects & 149 & & \\
\hline Age & $44.1 \pm 14.1$ & 21 & 69 \\
\hline Height (cm) & $170.2 \pm 5.6$ & 158.1 & 187.3 \\
\hline Body weight (kg) & $66.4 \pm 8.8$ & 48.3 & 96.4 \\
\hline Body mass index $\left(\mathrm{kg} / \mathrm{m}^{2}\right)$ & $22.9 \pm 2.9$ & 17.2 & 34.7 \\
\hline Abdominal circumference $(\mathrm{cm})$ & $81.3 \pm 8$ & 63.9 & 104.9 \\
\hline Body fat percentage (\%) & $19.8 \pm 5.6$ & 27.3 & 60.4 \\
\hline Predicted oxygen uptake $(\mathrm{ml} / \mathrm{kg} / \mathrm{min})$ & $37.2 \pm 8.7$ & 16.5 & 61.9 \\
\hline Predicted work rate (watt) & $200.8 \pm 49.1$ & 91 & 354 \\
\hline Predicted heart rate (beat/min) & $178.6 \pm 23.2$ & 106 & 230 \\
\hline Daily step counts (steps/day) & $8588.7 \pm 3601.4$ & 973.0 & 20910.9 \\
\hline METs $\cdot h / w$ & $14.5 \pm 10.8$ & 0.0 & 63.4 \\
\hline
\end{tabular}

weight, abdominal circumference and body fat percentage. Abdominal circumference was measured at the umbilical level in standing subjects after normal exhalation [10]. Body fat percentage was measured by dual energy X-ray absorptiometry (DEXA) (QDR4500; Hologic Inc., Waltham, MA, USA), which is used as an accurate standard [11]. The DEXA measurement consisted of a whole body scan using an array beam [12]. Subjects removed all metal objects and were positioned in the supine position with hands placed prone on either side of the body and with legs held $10 \mathrm{~cm}$ apart according to the specifications of the manufacturer. All scans were analyzed according to the manufacturer's instructions [13].

\subsection{Exercise Testing}

Predicted oxygen uptake was measured using a maximal graded exercise test with bicycle ergometers (Excalibur V2.0; Lode BV, Groningen, Netherlands). The initial work load was 30 - 60 watt, and the work rate was increased thereafter by $15 \mathrm{watt} / \mathrm{min}$ until the subject could not maintain the required pedaling frequency (60 rpm) [14]. During the latter stages of the test, each subject was verbally encouraged by the test operators to make their maximal effort. In addition, ECG was monitored continuously together with recording of the heart rate (HR). Expired gas was collected and rates of oxygen consumption $\left(\mathrm{VO}_{2}\right)$ and carbon dioxide production $\left(\mathrm{VCO}_{2}\right)$ were measured breath-by-breath using a cardiopulmonary gas exchange system (Oxycon Alpha; Mijnhrdt b.v., Netherlands). Achievement of predicted oxygen uptake was accepted if two of the following con- ditions were met: subject's maximal HR was $>95 \%$ agepredicted maximal $\mathrm{HR}(220-$ age $)$, and the $\mathrm{VO}_{2}$ curve showed a leveling off.

\subsection{Cigarette Smoking}

Data on cigarette smoking were obtained at interviews by well-trained hired staff, such as a public health nurse, in a structured way. The subjects were asked if they currently or had previously smoked cigarettes for at least 6 months and/or 100 cigarettes. When the answer was "yes", they were classified as cigarette smokers $(+)$. When the answer was "no", they were classified as cigarette smokers (-).

\subsection{Physical Activity}

Physical activity was measured by the Kenz Lifecorder (LC; SUZUKEN Co Ltd, Nagoya, Japan) which is a recent addition to the growing number of uniaxial accelerometer options; it offers comparable instrument outputs with several potentially attractive features for researchers and practitioners. The LC displays reasonable estimates of physical activity intensity and energy expenditures under controlled conditions on a treadmill [15], over $24 \mathrm{~h}$ of typical daily activities undertaken in a respiratory chamber [15], and in a free-living environment using double-labeled water as the criterion method [16]. Furthermore, when compared with many other accelerometers, the LC can potentially simplify the data interpretation process by reducing the time spent and the need for advanced technical expertise or software programs [17]. The subjects were taught how to use the in- 
strument, and were told to wear it on their belt or waist band at the right midline of the thigh from the moment they got up until they went to bed except while bathing or swimming, for seven consecutive days [18]. The activity monitor was firmly attached to their clothes at the waist by a clip.

\subsection{Statistical Analysis}

All data are expressed as the mean \pm standard deviation (SD). Statistical analysis was performed using the unpaired $t$ test and covariance analysis, with $p<0.05$ considered significant. We used the unpaired $t$ test to compare parameters between subjects who did and did not smoke cigarettes. Pearson's correlation coefficients were calculated and used to test the significance of the linear relationship between continuous parameters.

\section{RESULTS}

The measurements of parameters in men are shown in Table 1. Predicted oxygen uptake in enrolled subjects was $37.2 \pm 8.7 \mathrm{ml} / \mathrm{kg} / \mathrm{min}$. Physical activity evaluated by LC according to $\Sigma$ [metabolic equivalents $\times$ h per week $(\mathrm{METs} \cdot \mathrm{h} / \mathrm{w})]$ was $14.5 \pm 10.8 \mathrm{METs} \cdot \mathrm{h} / \mathrm{w}$. Seventy-eight men $(52.3 \%)$ were defined as having a smoking habit (Table 2).

We evaluated the relationship between age and clinical parameters such as predicted oxygen uptake, predicted work rate, predicted heart rate, daily step counts and METs $\cdot h / w$ (Table 3). Predicted oxygen uptake, predicted work rate and predicted heart rate were significantly correlated with age (Table 3, Figure 1).

In men, there was significant difference in age between subjects who did and did not smoke cigarettes. Predicted oxygen uptake [smoking habit $(+): 34.1 \pm 7.5$ $\mathrm{ml} / \mathrm{kg} / \mathrm{min}$, smoking habit $(-): 40.7 \pm 8.7 \mathrm{ml} / \mathrm{kg} / \mathrm{min}]$, predicted work rate and predicted heart rate in men who smoked cigarettes were significantly lower than in men who did not (Table 4). Significant differences of daily step counts and METs $\cdot h / w$ were not noted between men who did and did not smoke cigarettes. To avoid the influence of age on parameters, we used age as a covariate

Table 2. Prevalence of subjects who smoked cigarettes.

\begin{tabular}{ccccccc}
\hline & $20 \mathrm{~s}$ & $30 \mathrm{~s}$ & $40 \mathrm{~s}$ & $50 \mathrm{~s}$ & $60 \mathrm{~s}$ & Total (\%) \\
\hline Smoking habit (+) & $4(13.3)$ & $13(43.3)$ & $20(66.7)$ & $20(64.5)$ & $21(75.0)$ & $78(52.3)$ \\
Smoking habit (-) & $26(86.7)$ & $17(56.7)$ & $10(33.3)$ & $11(35.5)$ & $7(25.0)$ & $71(47.7)$ \\
\hline
\end{tabular}

Table 3. Relationship between age and clinical parameters.

\begin{tabular}{lcc}
\hline & $\mathrm{r}$ & $p$ \\
\hline Predicted oxygen uptake $(\mathrm{ml} / \mathrm{kg} / \mathrm{min})$ & -0.554 & $<0.0001$ \\
Predicted work rate (watt) & -0.554 & $<0.0001$ \\
Predicted heart rate (beat/min) & -0.719 & $<0.0001$ \\
Daily step counts (steps/day) & 0.114 & 0.1657 \\
METs $/ \mathrm{h} / \mathrm{w}$ & 0.124 & 0.1305 \\
$\Sigma[$ metabolic equivalents $\times \mathrm{h}$ per week $(\mathrm{METs} / \mathrm{h} / \mathrm{w})]$ & & \\
\hline
\end{tabular}

Table 4. Comparison of aerobic exercise level between men with and without a cigarette smoking habit.

\begin{tabular}{|c|c|c|c|c|c|}
\hline & Smoking habit $(+)$ & Smoking habit (-) & $p$ & After adjusting for age & $\begin{array}{l}\text { After adjusting for } \\
\text { age and METs } \cdot h / w\end{array}$ \\
\hline Age & $49.4 \pm 12.4$ & $38.3 \pm 13.7$ & $<0.0001$ & & \\
\hline $\begin{array}{l}\text { Predicted oxygen uptake } \\
(\mathrm{ml} / \mathrm{kg} / \mathrm{min})\end{array}$ & $34.1 \pm 7.5$ & $40.7 \pm 8.7$ & $<0.0001$ & 0.0415 & 0.0632 \\
\hline Predicted work rate (watt) & $184.4 \pm 40.8$ & $218.9 \pm 51.3$ & $<0.0001$ & 0.0351 & 0.0873 \\
\hline $\begin{array}{l}\text { Predicted heart rate } \\
\text { (beat } / \mathrm{min} \text { ) }\end{array}$ & $172.5 \pm 22.0$ & $185.3 \pm 22.6$ & 0.0006 & 0.9942 & 0.6278 \\
\hline $\begin{array}{l}\text { Daily step counts } \\
\text { (steps/day) }\end{array}$ & $8401.0 \pm 3922.6$ & $8794.9 \pm 3227.3$ & 0.5067 & 0.9655 & 0.9639 \\
\hline METs $\cdot h / w$ & $14.6 \pm 11.7$ & $14.4 \pm 9.8$ & 0.9171 & 0.7842 & \\
\hline
\end{tabular}




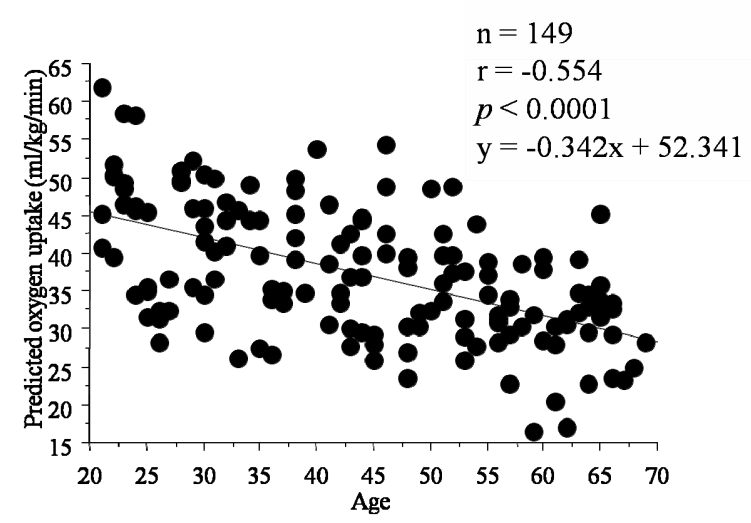

Figure 1. Simple correlation analysis between predicted oxygen uptake and age.

and compared parameters using covariance analysis. In addition, predicted oxygen uptake and predicted work rate with cigarette smoking were significantly lower than in men who did not smoke cigarettes even after adjusting for age (Table 4).

It is well known that the aerobic exercise level is closely linked to exercise habits [19]. To avoid the influence of age and exercise habits evaluated by METs $\cdot h / w$ on cigarette smoking, we finally used age and METs $\cdot h / w$ as covariates and compared parameters using covariance analysis. Significant differences of predicted oxygen uptake and predicted work rate between men with and without smoking habits were attenuated after adjusting for age and METs $\cdot \mathrm{h} / \mathrm{w}$ (predicted oxygen uptake: $p=$ 0.0632, predicted work rate: $p=0.0873$ ) (Table 4).

\section{DISCUSSION}

Impairment of pulmonary oxygen exchange [20,21], down regulation of adrenergic receptors [22] and longterm cardiac damage caused by stimulation of catecholamine by smoking [23] may also in part explain the lower maximal oxygen uptake in men who smoked cigarettes. Some cross sectional studies show that cigarette smoking is correlated with cardiovascular fitness [24-27]. Rotstein et al. reported that smoking retards physiological responses to submaximal exercise immediately after smoking three cigarettes [24]. Hirsch et al. evaluated the immediate effects of cigarette smoking on aerobic exercise capacity, which resulted in a significantly lower $\mathrm{VO}_{2}$ max and higher heart rate after 3 cigarettes/h for 5 hours [25]. Marti et al. also showed that, among army conscripts, the distance covered in a 12-min endurance run was inversely related to daily cigarette consumption and years of smoking [26]. Bolinder et al. reported that significantly lower maximal oxygen uptake was found for smokers than non-smokers [27]. We also reported that oxygen uptake at the ventilatory threshold (VT) in women and work rate at VT in men who smoked cigarettes were significantly lower than in subjects who did not smoke cigarettes, after adjusting for age [28]. The differences of parameters at VT did not reach significant levels after adjusting for age and exercise habits in both sexes [28]. In longitudinal analysis, Sandvik L. et al. showed that decline in physical fitness and lung function was greater among smokers than among non-smokers among 1393 men over 7 years [29]. Moreover, moderate to heavy smoking was longitudinally and negatively related to maximal oxygen uptake, maximum treadmill slope, heat rate at sub-maximal exercise and maximum heat rate, and with increasing age, the negative relationship between smoking and the parameters described above became stronger in men [30]. In this study, we solely evaluated the relationship between cigarette smoking and the aerobic exercise level defined by predicted oxygen uptake in Japanese men. Physical activeity was accurately evaluated by LC and the aerobic exer cise level was also accurately measured by predicted oxygen uptake compared to our previous studies [28]. Predicted oxygen uptake and predicted work rate in men who smoked cigarettes were lower than in men who did not smoke cigarettes after adjusting for age and METs $\cdot h / w$, but not at a significant level. Taken together, a combination of increased physical activity and giving up cigarette smoking might be considered for improving predicted oxygen uptake in Japanese men.

Potential limitations remain in this study. First, our study was a cross sectional and not a longitudinal study. Second, the 149 men in our study voluntarily underwent measurements; they were therefore more likely to be more health-conscious than the average person. Third, we could not show a clear relationship between cigarette smoking and predicted oxygen uptake because of the small sample size in this study. Fourth, the relationship between cigarette smoking and predicted oxygen uptake was not investigated in women; however, it seems reasonable to suggest that giving up smoking and increasing physical activity might ameliorate the aerobic exercise level in some Japanese men. To show this, further prospective studies of Japanese are needed.

\section{ACKNOWLEDGEMENTS}

This research was supported in part by Research Grants from the Ministry of Health, Labor, and Welfare, Japan. There is no conflict of interest.

\section{REFERENCES}

[1] Miyatake, N., Takahashi, K., Wada, J., Nishikawa, H., Morishita, A., Suzuki, H., Kunitomi, M., Makino, H., Kira, S. and Fujii, M. (2003) Daily exercise lowers blood pressure and reduces visceral fat in overweight Japanese men. Diabetes Research and Clinical Practice, 62, 149-157. 
doi:10.1016/S0168-8227(03)00176-1

[2] Barnard, R.J., Ugianskis, E.J., Martin, D.A. and Inkeles, S.B. (1992) Role of diet and exercise in the management of hyperinsulinemia and associated atherosclerotic risk factors. The American Journal of Cardiology, 69, 440-444. doi:10.1016/0002-9149(92)90981-4

[3] Yamanouchi, K., Shinozaki, T., Chikada, K., Nishikawa, T., Ito, K., Shimizu, S., Ozawa, N., Suzuki, Y., Maeno, H., Kato, K., Oshida, Y. and Sato, Y. (1995) Daily walking combined with diet therapy is a useful means for obese NIDDM patients not only to reduce body weight but also to improve insulin sensitivity. Diabetes Care, 18, 775-778. doi:10.2337/diacare.18.6.775

[4] Ohida, Y., Yamanouchi, K., Hayamizu, S. and Sato, Y. (1989) Long-term mild jogging increases insulin action despite no influence on body mass index or VO2 max. Journal of Applied Physiology, 66, 2206-2210.

[5] Miyatake, N., Nishikawa, H., Morishita, A., Kunitomi, M., Wada, J., Suzuki, H., Takahashi, K., Makino, H., Kira, S. and Fujii, M. (2002) Daily walking reduces visceral adipose tissue areas and improves insulin resistance in Japanese obese subjects. Diabetes Research and Clinical Practice, 58, 101-107. doi:10.1016/S0168-8227(02)00129-8

[6] Sandvik, L., Erikssen, J., Thaulow, E., Erikssen, G., Mundal, R. and Rodahl, K. (1993) Physical fitness as a predictor of mortality among healthy, middle-aged Norwegian men. The New England Journal of Medicine, 25, 533537. doi:10.1056/NEJM199302253280803

[7] Ministry of Health, Labour and Welfare, Japan (2011) Exercise and physical activity reference for health promotion 2006. http://www.mhlw.go.jp/bunya/kenkou/undou01/pdf/data.pdf

[8] Ministry of Health, Labour and Welfare, Japan (2011) The National Nutrition Survey in Japan. http://www.mhlw.go.jp/houdou/2008/12/d1/h1225-5j.pdf

[9] Peto, R. (1994) Smoking and death: The past 40 years and the next 40. British Medical Journal, 209, 937-939. doi:10.1136/bmj.309.6959.937

[10] Committee to Evaluate Diagnostic Standards for metabolic Syndrome (2005) Definition and the diagnostic standard for metabolic syndrome - Committee to Evaluate Diagnostic Standards for Metabolic Syndrome. Nippon Naika Gakkai Zasshi, 94, 794-809.

[11] Wang, J., Heymsfield, S.B., Aulet, M., Thornton, J.C. and Pierson, R.N. Jr. (1989) Body fat from body density: Underwater weighing vs. dual-photon absorptiometry. American Journal of Physiology, 256, E829-E834.

[12] Gustafsson, L., Jacobson, B. and Kusoffsky, L. (1974) X-ray spectrophotometry for bon-mineral determinations. Journal of Medical \& Biological Engineering, 12, 113-119.

[13] Herd, R.J., Blake, G.M., Parker, J.C., Ryan, P.J. and Fogelman, I. (1993) Total body studies in normal British women using dual energy X-ray absorptiometry. British Journal of Radiology, 66, 303-308. doi:10.1259/0007-1285-66-784-303

[14] Miyachi, M., Tanaka, H., Yamamoto, K., Yoshioka, A., Takahashi, K. and Onodera, S. (2001) Effects of onelegged endurance training on femoral arterial and venous size in healthy humans. Journal of Applied Physiology,
90, 2439-2444.

[15] Kumahara, H., Schutz, Y., Ayabe, M., Yoshioka, M., Yoshitake, Y., Shindo, M., Ishii, K. and Tanaka, H. (2004) The use of uniaxial accelerometry for the assessment of physical-activity-related energy expenditure: A validation study against whole-body indirect calorimetry. British Journal of Nutrition, 91, 235-243. doi:10.1079/BJN20031033

[16] Yamada, Y., Yokoyama, K., Noriyasu, R., Osaki, T., Adachi, T., Itoi, A., Naito, Y., Morimoto, T., Kimura, M. and Oda, S. (2009) Light-intensity activities are important for estimating physical activity energy expenditure using uniaxial and triaxial accelerometers. European Journal of Applied Physiology, 105, 141-152. doi:10.1007/s00421-008-0883-7

[17] McClain, J.J., Sisson, S.B., Washington, T.L., Craig, C.L. and Tudor-Locke, C. (2007) Comparison of Kenz Lifecorder EX and ActiGraph accelerometers in 10-yr-old children. Medicine \& Science in Sports \& Exercise, 39, 630-638. doi:10.1249/mss.0b013e3180313056

[18] Clemes, S.A. and Griffiths, P.L. (2008) How many days of pedometer monitoring predict monthly ambulatory activity in adults? Medicine \& Science in Sports \& Exercise, 40, 1589-1595. doi:10.1249/MSS.0b013e318177eb96

[19] Miyatake, N., Saito, T., Wada, J., Miyachi, M., Tabata, I., Matsumoto, S., Nishikawa, H., Makino, H. and Numata, T. (2007) Comparison of ventilatory threshold and exercise habits between Japanese men with and without metabolic syndrome. Diabetes Research and Clinical Practice, 77, 314-319. doi:10.1016/j.diabres.2006.11.008

[20] Powers, S.K., Lawler, J., Dempsey, J.A., Dodd, S. and Landry, G. (1989) Effects of incomplete pulmonary gas exchange on VO2 max. Journal of Applied Physiology, 66, 2491-2495.

[21] Green, M.S., Jucha, E. and Luz, Y. (1986) Blood pressure in smokers and nonsmokers: Epidemiologic findings. American Heart Journal, 111, 932-940. doi:10.1016/0002-8703(86)90645-9

[22] Laustiola, K.E., Lassila, R., Kaprio, J. and Koskenvuo, M. (1988) Decreased beta-adrenergic receptor density and catecholamine response in male cigarette smokers. A study of monozygotic twin pairs discordant for smoking. Circulation, 78, 1234-1240. doi:10.1161/01.CIR.78.5.1234

[23] Cryer, P.E., Haymond, M.W., Santiago, J.V. and Shah, S.D. (1976) Norepinephrine and epinephrine release and adrenergic mediation of smoking-associated hemodynamic and metabolic events. The New England Journal of Medicine, 295, 573-577. doi:10.1056/NEJM197609092951101

[24] Rotstein, A., Sagiv, M., Yaniv-Tamir, A., Fisher, N. and Dotan, R. (1991) Smoking effect on exercise response kinetics of oxygen uptake and related variables. International Journal of Sports Medicine, 12, 281-284. doi:10.1055/s-2007-1024681

[25] Hirsch, G.L. and Sue, D.Y., Wasserman, K., Robinson, T.E. and Hansen, J.E. (1985) Immediate effects of cigarette smoking on caridiorespiratory responses to exercise. Journal of Applied Physiology, 58, 1975-1981.

[26] Marti, B., Abelin, T., Minder, C.E. and Vader, J.P. (1988) 
Smoking, alcohol consumption, and endurance capacity: An analysis of 6500 19-year-old conscripts and 4100 joggers. Preventive Medicine, 17, 79-92. doi:10.1016/0091-7435(88)90074-6

[27] Bolinder, G., Noren, A., Wahren, J. and De Faire, U. (1997) Long-term use of smokeless tobacco and physical performance in middle-aged men. European Journal of Clinical Investigation, 27, 427-433. doi:10.1046/j.1365-2362.1997.1290677.x

[28] Miyatake, N., Numata, T., Nishii, K., Sakano, N., Suzue, T., Hirao, T., Miyachi, M. and Tabata, I. (2011) The relation between cigarette smoking and ventilatory threshold in the Japanese. Environmental Health and Preventive Medicine, 16, 185-190. doi:10.1007/s12199-010-0178-6

[29] Sandvik, L., Erikssen, G. and Thaulow, E. (1995) Long term effects of smoking on physical fitness and lung function: A longitudinal study of 1393 middle aged Norwegian men for seven years. British Medical Journal, 311, 715-718. doi:10.1136/bmj.311.7007.715

[30] Bernaards, C.M., Twisk, J.K., Van, Mechelen, W., Snel, J. and Kemper, H.C. (2003) A longitudinal study on smoking in relationship to fitness and heat rate response. Medicine \& Science in Sports \& Exercise, 35, 793-800. doi:10.1249/01.MSS.0000064955.31005.E0 